\title{
BIBECHANA
}

A Multidisciplinary Journal of Science, Technology and Mathematics ISSN 2091-0762 (Print), 2382-5340 (Online)

Journal homepage: http://nepjol.info/index.php/BIBECHANA

Publisher: Research Council of Science and Technology, Biratnagar, Nepal

\section{Energetics and local order in In-based liquid alloys}

\author{
R. P. Koirala ${ }^{1,2^{*}}$, B. P. Singh ${ }^{1}$, I.S. Jha ${ }^{2}$, D. Adhikari ${ }^{2}$ \\ ${ }^{1}$ University Department of Physics, T.M. Bhagalpur University, Bhagalpur, India \\ ${ }^{2}$ Department of Physics, M.M.A.M. Campus, Biratnagar, Tribhuvan University, Nepal \\ E-mail: rpphysics@ gmail.com
}

Article history: Received 05 June, 2015; Accepted 20 August, 2015

DOI: http://dx.doi.org/10.3126/bibechana.v13i0.13359

\section{Abstract}

A comparative study has been carried out to understand the concentration dependence of thermodynamic properties such as, free energy of mixing $\left(G_{M}\right)$, heat of mixing $\left(H_{M}\right)$, entropy of mixing $\left(S_{M}\right)$, activity $\left(\mathrm{a}_{\mathrm{i}}\right)$ and microscopic properties, such as concentration fluctuation in long wavelength limit $\left(\mathrm{S}_{\mathrm{CC}}(0)\right)$ and Warren-Cowley short range order parameter $\left(\alpha_{1}\right)$ of In-based three liquid alloys (In-Pb, In-Tl and In-Zn) on the basis of self-association model. The analysis reveals that self-association model successfully explains the observed properties of the liquid alloys. Positive deviation of the thermodynamic properties of the alloys from the Raoultian solution behaviour indicates that the alloys are weakly segregating in nature. The comparative assessment of the interaction energy and the microscopic properties suggests that the degree of segregation is greatest in In- $\mathrm{Zn}$ alloy and comparable in In- $\mathrm{Pb}$ and $\mathrm{In}-\mathrm{Tl}$ alloys.

ORCOST: All rights reserved.

Keywords: Liquid alloys; Self association model; Order energy; Segregation.

\section{Introduction}

Preliminary ideas about the mixing of metals in a binary alloy can be deduced from Hume-Rothery rules for metallic solution which describe condition for forming substitutional and interstitial solutions. Experience shows that the Hume-Rothery factors, such as the valence difference, electro-negativity difference and atomic size mismatch are not sufficient to provide detail information for understanding the alloying of metals in the liquid phase, and for this reason, properties of mixing are considered. The properties of mixing in a liquid alloy at a given temperature and pressure are ascribed to the role of some sort of short range microscopic interactions which are assumed to exist in a micro-inhomogeneous atomic distribution giving rise to the equilibrium properties of the alloy. The accurate determination of the interaction energy terms in liquid alloy is usually a difficult task as compared to those in ordered systems 
like crystals. Thus there always remains an opportunity for the prediction of the true character of atomic interaction in a liquid alloy so that the observed properties of mixing could be explained adequately.

The mixing behaviour of binary liquid alloys is described as ordering or segregating depending on the nature of arrangement of atoms of the constituent metals in the alloys. Alloys of ordering nature are characterized by the pairing of unlike atoms leading to the formation of chemical complexes. Segregating alloys, on the other hand, have pairing of like atoms at equivalent sites. It is known that many binary liquid alloys exhibit non-regular solution behaviour. The alloys of a versatile metal indium, such as $\mathrm{In}-\mathrm{Pb}$ $(673 \mathrm{~K})$, In-Tl $(723 \mathrm{~K})$ and $\mathrm{In}-\mathrm{Zn}(700 \mathrm{~K})$ in particular are interesting in that the observed thermodynamic properties of mixing like free energy of mixing and entropy of mixing are asymmetrical to some extent about the equiatomic composition [1]. The positive sign of observed heat of mixing for these alloys and the concentration fluctuation in long wavelength limit $\left(\mathrm{S}_{\mathrm{CC}}(0)\right)$ of the alloys calculated from the observed activity data indicate that the alloys show positive deviations from the additive rule of mixing. Since long, many studies have been carried out to understand the alloying behaviour of various liquid alloys in different concerns [2-21]. Of the models the self-association model $[4,8,12]$ is considered appropriate for the study of the equilibrium thermodynamic and structural properties of binary liquid alloys endowed with segregating nature. This model is the approximation over the compound formation model when no chemical complex is assumed to exist in the binary alloy melt $[2,14]$.

Over times, various studies have been carried out for the study of the mixing properties of In- $\mathrm{Pb}$, In-Tl and $\mathrm{In}-\mathrm{Zn}$ alloys in different concerns [22-31]. In this paper we aim to review alloying behaviour in the three In-based liquid alloys, In-Pb $(673 \mathrm{~K})$, In-Tl $(723 \mathrm{~K})$ and $\mathrm{In}-\mathrm{Zn}(700 \mathrm{~K})$ by computing the concentration dependence of thermodynamic properties such as, free energy of mixing $\left(G_{M}\right)$, heat of mixing $\left(\mathrm{H}_{\mathrm{M}}\right)$, entropy of mixing $\left(\mathrm{S}_{\mathrm{M}}\right)$, activity $\left(\mathrm{a}_{\mathrm{i}}\right)$ and microscopic functions, such as the concentration fluctuation in long wavelength limit and the short range order parameter, as function of concentration in the light of this self-association model. In the following section, we present the necessary theoretical expressions required for the computation of thermodynamic and the microscopic functions of binary liquid alloys, which is followed by result and a discussion of the work in section 3 and conclusions in section 4.

\section{Theoretical basis}

The self-association model is a simple scheme for demixing binary liquid alloys [8, 12]. It assumes pairing of like atoms at equivalent sites that have short-ranged interaction between nearest neighbours. Such homo-coordination of atoms leads to the formation of self-associates in the alloys. Let a liquid binary A-B alloy consist of $\mathrm{N}_{\mathrm{A}}=\mathrm{cN}$ atoms of element $\mathrm{A}$ and $\mathrm{N}_{\mathrm{B}}=(1-\mathrm{c}) \mathrm{N}$ atoms of element $\mathrm{B}$ which form like atom clusters or self-associates of type $\mu \mathrm{A}$ and $\nu \mathrm{B}$, where $\mu$ and $\nu$ are the number of atoms in the clusters of type A and B matrices respectively. On the basis of this assumption the expressions for thermodynamic and microscopic functions are derived for binary liquid alloy. 


\subsection{Thermodynamic properties}

In the self-association model, the free energy of mixing, $G_{M}$ for binary liquid alloys at temperature $T$ can be obtained using the following expression [12]:

$$
\Delta \mathrm{G}_{\mathrm{M}}=\mathrm{RT}[\mathrm{c} \ln \mathrm{c}+(1-\mathrm{c}) \ln (1-\mathrm{c})+\mathrm{c} \ln (1-\xi)+\ln \Gamma]+\mathrm{c}(1-\mathrm{c}) \Gamma \mathrm{W}
$$

where, $\mathrm{R}$ is universal gas constant, $\mathrm{c}$ is concentration of A-atoms in the alloy and $\mathrm{W}$ is order energy parameter. The auxiliary functions $\xi$ and $\Gamma$ are defined as

$$
\xi=1-1 / \gamma, \quad \Gamma=1 /(1-c \xi)
$$

where $\gamma=v / \mu(\nu \neq \mu)$ is called the ratio of self-associates. At a given temperature $\gamma$ and W are the model parameters of self-association model which are estimated for a liquid alloy by fitting them into experimental thermodynamic data of the alloy to estimate the thermodynamic and structural properties of a binary liquid alloy.

In order to obtain the expression for the activity, $a_{i}$ of constituent element in a binary liquid alloy the following standard thermodynamic relation, which relates activity, $a_{i}$ to the free energy of mixing, $G_{M}$ is used:

$$
R T \ln \mathrm{a}_{\mathrm{i}}=\Delta \mathrm{G}_{\mathrm{M}}+(1-\mathrm{c}) \frac{\partial\left(\Delta \mathrm{G}_{\mathrm{M}}\right)}{\partial \mathrm{c}} \quad(\text { where } \mathrm{i}=\mathrm{A}, \mathrm{B})
$$

From Eqs. (1) and (2), we get

$$
\ln \mathrm{a}_{\mathrm{A}}=\ln [\mathrm{c} \Gamma(1-\xi)]+(1-\mathrm{c}) \xi \Gamma+(1-\mathrm{c})^{2} \Gamma^{2} \frac{\mathrm{W}}{\mathrm{RT}}
$$

and

$$
\ln \mathrm{a}_{\mathrm{B}}=\ln (\mathrm{c} \Gamma)+\mathrm{c}(1-\xi) \Gamma(1-\gamma)+\mathrm{nc}^{2}(1-\xi) \Gamma^{2} \frac{\mathrm{W}}{\mathrm{RT}}
$$

The entropy of mixing, $S_{M}$ for binary alloys can be obtained using the thermodynamic relation

$$
\Delta \mathrm{S}_{\mathrm{M}}=-\frac{\partial\left(\Delta \mathrm{G}_{\mathrm{M}}\right)}{\partial \mathrm{T}}
$$

By the differentiation of the expression for $G_{M}$ in Eqn. (1) is obtained as

$$
\Delta \mathrm{S}_{\mathrm{M}}=-\mathrm{R}[\mathrm{c} \ln \mathrm{c}+(1-\mathrm{c}) \ln (1-\mathrm{c})+\mathrm{c} \ln (1-\xi)+\ln \Gamma]+\mathrm{c}(1-\mathrm{c}) \Gamma \frac{\partial \mathrm{W}}{\partial \mathrm{T}}
$$


The heat of mixing, $\mathrm{H}_{\mathrm{M}}$ can be calculated from the knowledge of the free energy of mixing and the entropy of mixing, using the standard thermodynamic relation

$$
\Delta \mathrm{H}_{\mathrm{M}}=\Delta \mathrm{G}_{\mathrm{M}}+\mathrm{T} \Delta \mathrm{S}_{\mathrm{M}}
$$

\subsection{Microscopic properties}

The microscopic functions such as concentration fluctuation in long wavelength limit, $\mathrm{S}_{\mathrm{CC}}(0)$ and WarrenCowley short-range order parameter, $\alpha_{1}$ are useful properties to obtain valuable information about structure of binary liquid alloys $[2,8] . \mathrm{S}_{\mathrm{cc}}(0)$ indicates the nature of local arrangement of atoms and $\alpha_{1}$ represents the degree of atomic ordering in the melt.

The standard relation for concentration fluctuation in long wavelength limit $\left(\mathrm{S}_{\mathrm{CC}}(0)\right)$ for binary liquid alloys is given as

$$
\mathrm{S}_{\mathrm{cc}}(0)=\mathrm{RT}\left[\frac{\partial^{2}\left(\Delta \mathrm{G}_{\mathrm{M}}\right)}{\partial \mathrm{c}^{2}}\right]_{\mathrm{T}, \mathrm{P}, \mathrm{N}}^{-1}
$$

The analytical expression for concentration fluctuation in long wavelength limit, $\mathrm{S}_{\mathrm{CC}}(0)$ in self-association model is obtained from Eq. (8) by taking the second composition derivative of the expression for $G_{M}$, from Eqs. (1) and it can be put in the following form [12]:

$$
S_{c c}(0)=\frac{c(1-c)}{1-c(1-c) f(\gamma, W)}
$$

where

$$
\mathrm{f}(\gamma, \mathrm{W})=\frac{2 \gamma^{2}(\mathrm{~W} / \mathrm{RT})-(\gamma-1)^{2}[\mathrm{c}+\gamma(1-\mathrm{c})]}{[\mathrm{c}+\gamma(1-\mathrm{c})]^{3}}
$$

The value of $\mathrm{S}_{\mathrm{cc}}(0)$ can also be obtained by taking the first composition derivative of the activity as given below [8]:

$$
\mathrm{S}_{\mathrm{cc}}(0)=(1-\mathrm{c}) \mathrm{a}_{\mathrm{A}}\left(\partial \mathrm{a}_{\mathrm{A}} / \partial \mathrm{c}\right)_{\mathrm{T}, \mathrm{P}}^{-1}=\mathrm{ca} \mathrm{a}_{\mathrm{B}}\left(\partial \mathrm{a}_{\mathrm{B}} / \partial(1-\mathrm{c})\right)_{\mathrm{T}, \mathrm{P}}^{-1}
$$

In the literature, the $S_{c c}(0)$ determined by using the measured activity data in Eq. (11) is usually referred to as an experimental $\mathrm{S}_{\mathrm{cc}}(0)[8]$.

In order to ascertain the degree of local ordering of atoms in the alloy, Warren-Cowley short range order parameter, $\alpha_{1}$ can be estimated from the knowledge of the interchange energy parameter, W. For this parameter, the following expression is available $[2,8]$ :

$$
\alpha_{1}=\frac{\beta-1}{\beta+1},
$$


where $\beta$ is an auxiliary variable and is a function of composition defined by:

$$
\beta=\sqrt{1+4 \mathrm{c}(1-\mathrm{c})\left[\exp \left(2 \mathrm{~W} / \mathrm{zk}_{\mathrm{B}} \mathrm{T}\right)-1\right]}
$$

Here $\mathrm{z}$ represents the co-ordination number. In terms of the function $\beta$, the concentration fluctuation in long wavelength, $\mathrm{S}_{\mathrm{cc}}(0)$ can be expressed as $[2,8]$ :

$$
\mathrm{S}_{\mathrm{cc}}(0)=\frac{\mathrm{c}(1-\mathrm{c})}{1+1 / 2 \mathrm{z}(1 / \beta-1)}
$$

From Eqs. (12) and (14), the short range order parameter, $\alpha_{1}$ can be expressed in the following form:

$$
\alpha_{1}=\frac{S_{C C}(0)-S_{C C}^{\mathrm{id}}(0)}{(z-1) S_{C C}(0)+S_{C C}^{\text {id }}(0)}, \quad \text { with } S_{C C}^{\text {id }}(0)=c(1-c)
$$

\section{Results and Discussion}

\subsection{Thermodynamic Properties}

A significant amount of information on the mixing of liquid metals forming a binary alloy can be obtained from the analysis of the energetics in the alloy. In order to study the composition dependence of the energetics in a binary liquid alloy in the framework of self-association model, as stated before, the ratio of self-associates $\gamma$ and the order energy parameter $\mathrm{W}$ are required. In the present work, these parameters have been determined for the liquid In-Pb alloy at $673 \mathrm{~K}$, In-Tl alloy at $723 \mathrm{~K}$ and In-Zn alloy at 700 from the method of successive approximation by fitting them into the experimental data of the free energy of mixing, $G_{M}$ [1] in Eqs. (1) and the activities, $a_{i}$ [1] in Eqs. (3) and (4) simultaneously, over the whole range of composition. In In- $\mathrm{Zn}$ alloy the calculations have been done taking the concentration ' $c$ ' for $\mathrm{Zn-component} \mathrm{for} \mathrm{getting} \mathrm{better} \mathrm{results.} \mathrm{For} \mathrm{the} \mathrm{computation} \mathrm{of} \mathrm{the} \mathrm{entropy} \mathrm{of} \mathrm{mixing,} \mathrm{S}_{\mathrm{M}}$, in addition to the ratio of self-associates $\gamma$, the temperature derivative of the order energy parameter, $\frac{\partial \mathrm{W}}{\partial \mathrm{T}}$ is also needed. This has been estimated using the experimental data of the entropy of mixing, $S_{M}$ [1]. The best estimated values of the parameters for the liquid alloys have been listed as follows:

\begin{tabular}{lllll}
\hline Alloy & Temperature & $\gamma$ & $\mathrm{W}$ & $\frac{\partial \mathrm{W}}{\partial \mathrm{T}}$ \\
\hline $\mathrm{In}-\mathrm{Pb}$ & $673 \mathrm{~K}$ & 1.66 & 0.44 & -0.69 \\
$\mathrm{In}-\mathrm{Tl}$ & $723 \mathrm{~K}$ & 1.45 & 0.49 & +1.58 \\
$\mathrm{In}-\mathrm{Zn}$ & $700 \mathrm{~K}$ & 1.68 & 1.44 & +2.99 \\
\hline
\end{tabular}

The calculated values of $G_{M}$ of the alloys are compared with the corresponding experimental values [1] by plotting them against the concentration of In-component in Fig.1. The plot shows there is excellent agreement between the theoretical values and the experimental values for $\mathrm{In}-\mathrm{Pb}$ and $\mathrm{In}-\mathrm{Tl}$ alloys while in In- $\mathrm{Zn}$ alloy the two sets of the $\mathrm{G}_{\mathrm{M}}$ agree well in the whole range of concentration. 
Like the experimental values, the theoretical values of $G_{M}$ have been found to be the minimum at the equi-atomic composition in In-Pb and In-Tl alloys. However, in In-Zn alloy our analysis predicts the minimum value around $70 \%$ atomic composition of In-component. This is slightly different from the minimum experimental value which is reported to occur at $60 \%$ atomic composition of In-component. Of the three binary liquid alloys of indium, the calculations of the free energy of mixing suggest that there is weakest tendency of spontaneous mixing of the metals in the $\mathrm{In}-\mathrm{Zn}$ alloy at $700 \mathrm{~K}$ and it is found to increase in the direction of In-Pb alloy at $673 \mathrm{~K}$ and In-Tl alloy at $723 \mathrm{~K}$. The order energy parameter has been found to be positive in all the three alloys, which indicates that the atoms of the components in the alloys prefer to remain self-associated and the alloys are segregating in nature. The observed asymmetry in the free energy of mixing, $G_{M}$ of the alloys is well explained by the self-association model.

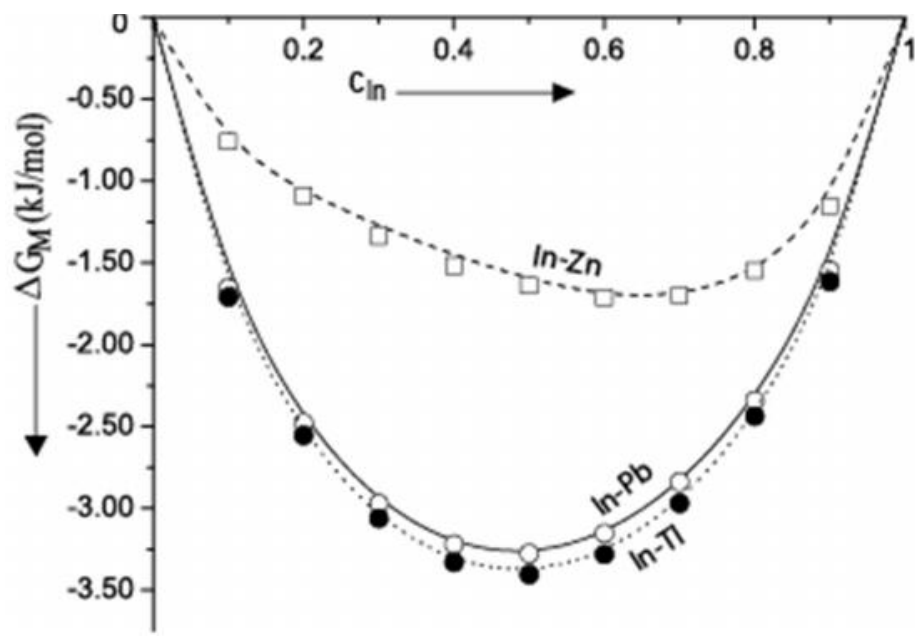

Fig. 1: Free energy of mixing, $\mathrm{G}_{\mathrm{M}}$ of liquid $\mathrm{In}-\mathrm{Pb}(673 \mathrm{~K})$, In-Tl $(723 \mathrm{~K})$ and In-Zn (700 K) alloys versus concentration, $\mathrm{c}_{\mathrm{In}}$ of In-component: Theory- curves: Solid [In-Pb]; Dotted [In-Tl]; Dash [In-Zn] Experiment-Symbols: circles [In-Pb]; sold circles [In-Tl]; squares [In-Zn].

The behaviour of the atoms in a binary liquid mixture can be accounted in terms of the chemical activity. The chemical activity is a measure of the tendency of the component to leave the solution. The deviations in the nature of a solution from ideal behaviour can be incorporated into activity. As in the case of free energy of mixing, the computed values of the chemical activities have been found to agree very well with the observed data [1] in the two alloys, In-Pb at $673 \mathrm{~K}$ and $\mathrm{In}-\mathrm{Tl}$ at $723 \mathrm{~K}$ at all concentrations and small discrepancies are observed in In-Zn alloy at $700 \mathrm{~K}$ (Fig. 2). It is clear from the plot that the activities, i.e. tendency of In-atoms to leave the metallic solution, are very comparable in the In-Pb and In-Tl alloys, with small positive deviation from the ideality. The In-Zn alloy is found to have large values for the 
activities of In-atoms, indicating that the alloy has the smallest tendency of mixing of the atoms in the alloy.

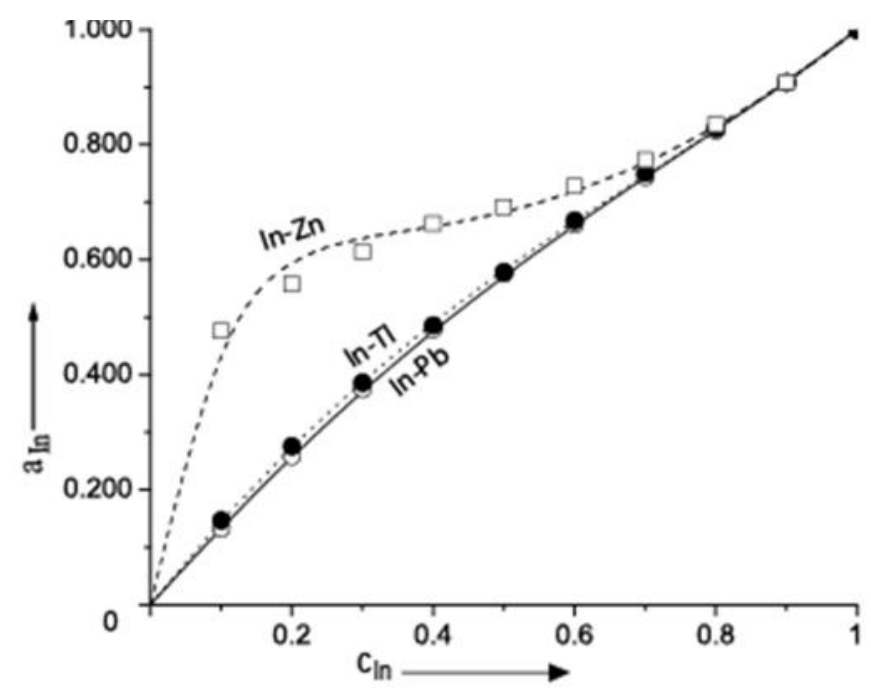

Fig. 2: Chemical activity, $\mathrm{a}_{\mathrm{In}}$ of In-component in liquid $\mathrm{In}-\mathrm{Pb}(673 \mathrm{~K})$, In-Tl $(723 \mathrm{~K})$ and $\mathrm{In}-\mathrm{Zn}$ $(700 \mathrm{~K})$ alloys versus concentration, $\mathrm{c}_{\mathrm{In}}$ of In-component: Theory- curves: Solid [In-Pb]; Dotted [In-Tl]; Dash [In-Zn] Experiment-Symbols: circles [In-Pb]; sold circles [In-Tl]; squares [In-Zn].

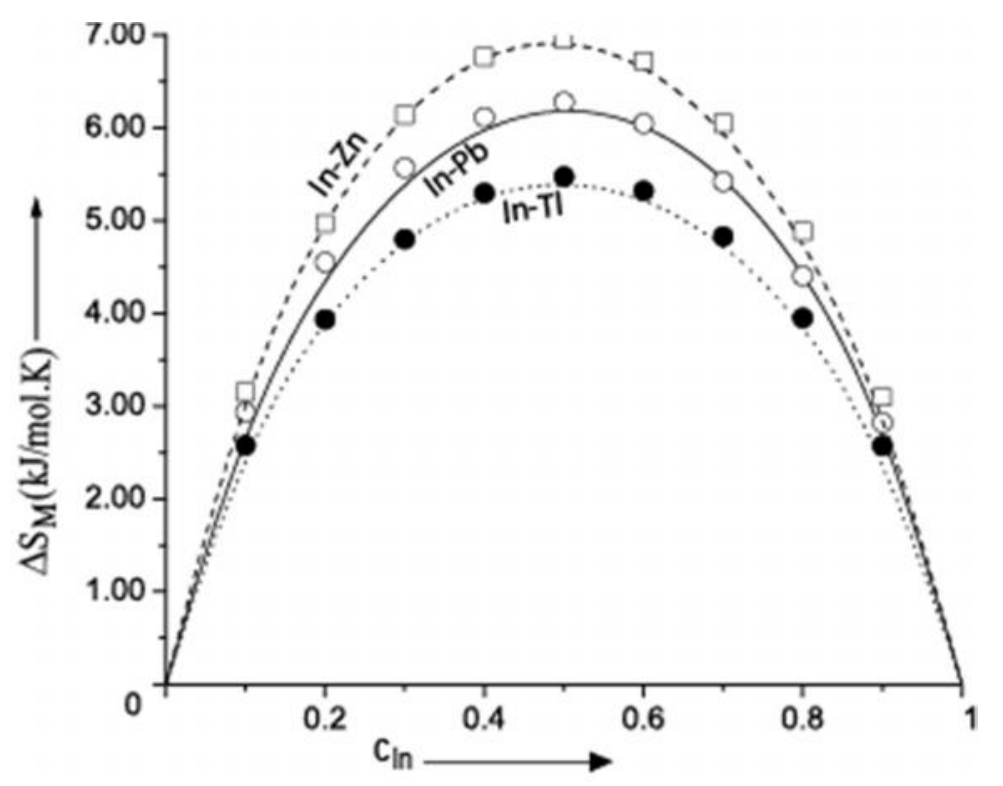

Fig. 3: Entropy of mixing, $S_{M}$ of liquid $\mathrm{In}-\mathrm{Pb}(673 \mathrm{~K})$, In-Tl (723 K) and In-Zn (700 K) alloys versus concentration, $c_{I n}$ of In-component: Theory- curves: Solid [In-Pb]; Dotted [In-Tl]; Dash [In$\mathrm{Zn}$ ]Experiment-Symbols: circles [In-Pb]; sold circles [In-Tl]; squares [In-Zn]. 
The inter-atomic interactions in a binary liquid alloy can also be described in terms of the enthalpic and entropic effects. The entropy of mixing which is a measure of disorderness in the local arrangement of atoms in the system indeed represents the sharing of energy between the atoms in the neighbourhood. The concentration dependence of the entropy of mixing, $S_{M}$ of the three alloys has been computed from Eq. (6) by estimating the temperature dependence of the energy parameter. The theoretical results for the alloys are compared in Fig. (3), along with the parallel experimental results [1].

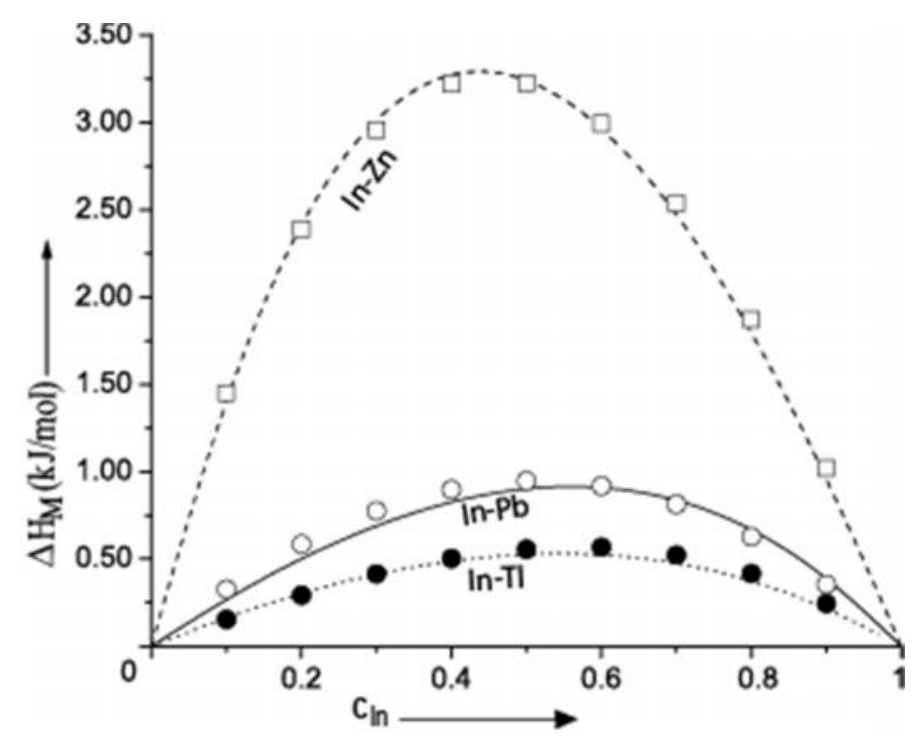

Fig. 4: Entropy of mixing, $\mathrm{H}_{\mathrm{M}}$ of liquid $\mathrm{In}-\mathrm{Pb}(673 \mathrm{~K})$, In-Tl $(723 \mathrm{~K})$ and $\mathrm{In}-\mathrm{Zn}(700 \mathrm{~K})$ alloys versus concentration, $\mathrm{c}_{\mathrm{In}}$ of In-component: Theory- curves: Solid [In-Pb]; Dotted [In-Tl]; Dash [In-Zn] Experiment-Symbols: circles [In-Pb]; sold circles [In-Tl]; squares [In-Zn].

The plot shows that the computed values of the entropy of mixing are in good agreement with the corresponding experimental values. The maximum in the calculated entropy of mixing of all the alloys have been found to occur at the equiatomic composition. This is in agreement with the observed results for the alloys.

Using the calculated values of the free energy of mixing and the entropy of mixing, we have computed the heat of mixing, $\mathrm{H}_{\mathrm{M}}$ for the alloys throughout the whole concentration range from Eq. (7). The computed results for $\mathrm{H}_{\mathrm{M}}$ in the alloys have been found to agree well with the corresponding experimental results [1], with a little deviation (Fig. 4). The small positive values of $H_{M}$ of the alloys suggest that each of the alloys belongs to system with the weak strength of the interatomic interactions showing a tendency of phase separation. 


\subsection{Microscopic properties}

In order to investigate the nature of local atomic ordering in the In- $\mathrm{Pb}$, In- $\mathrm{Tl}$ and $\mathrm{In}-\mathrm{Zn}$ liquid alloys in more detail, we have computed microscopic functions, the concentration fluctuations in long wavelength limit, $\mathrm{S}_{\mathrm{CC}}(0)$ from Eqs. (9) and (10). The computed and experimental values of $\mathrm{S}_{\mathrm{CC}}(0)$ along with the ideal values are compared by plotting them as function of concentration in Fig. 5. In our analysis, both the theoretical and experimental values of $\mathrm{S}_{\mathrm{CC}}(0)$ have been found to be greater than the corresponding ideal values in all liquid alloys at all concentrations (Fig. 5). This clearly suggests that the indium based alloys under study have preference of like atom pairing over hetero-pairing of atoms.

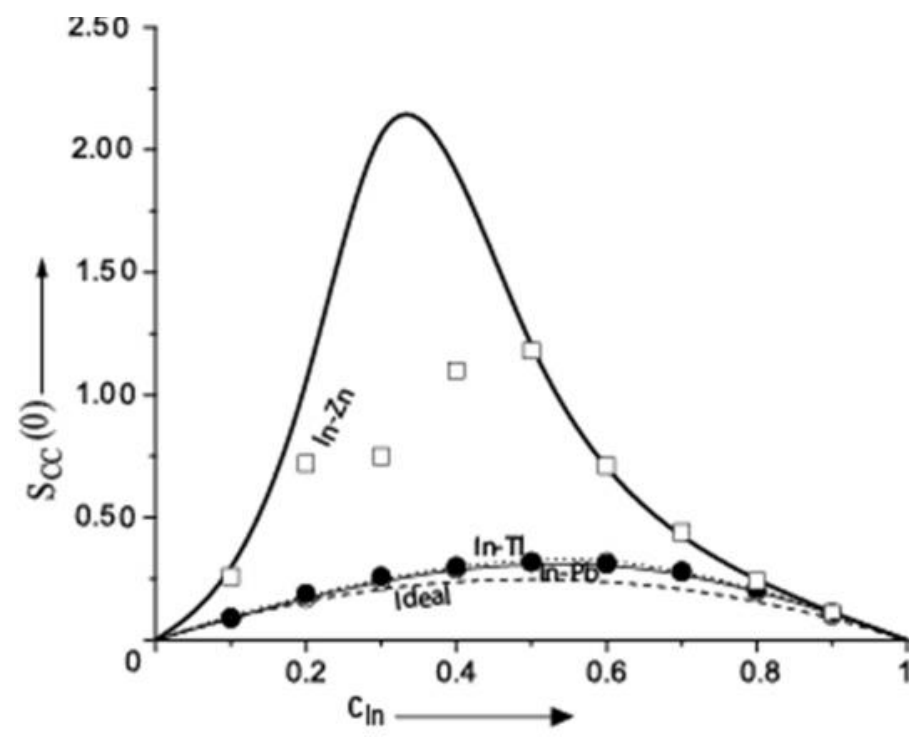

Fig. 5: Concentration fluctuation in long wavelength limit, $\mathrm{S}_{\mathrm{CC}}(0)$ of liquid $\mathrm{In}-\mathrm{Pb}(673 \mathrm{~K})$, In-Tl (723 K) and $\mathrm{In}-\mathrm{Zn}(700 \mathrm{~K})$ alloys versus concentration, $\mathrm{c}_{\mathrm{In}}$ of In-component: Theory- curves: Thin solid [In$\mathrm{Pb}$; Dotted [In-Tl]; thick solid [In-Zn]; Dash [Ideal] Experiment-Symbols: circles [In-Pb]; solid circles [In-Tl]; squares [In-Zn].

The structure regarding the atomic ordering in the liquid alloys has been additionally accessed by computing the Warren-Cowely short range ordering parameter, $\alpha_{1}$ using Eq. (15) throughout the composition range. The short range parameter has been found to be positive at all concentrations for the alloys (Fig. 6). In our calculation we have taken $Z=10$. We note that on varying the value of $Z$, the peak value in $\alpha_{1}-c$ curve changes but the nature of variation and position of the peak in the value of $\alpha_{1}$ against concentration remain unchanged. 


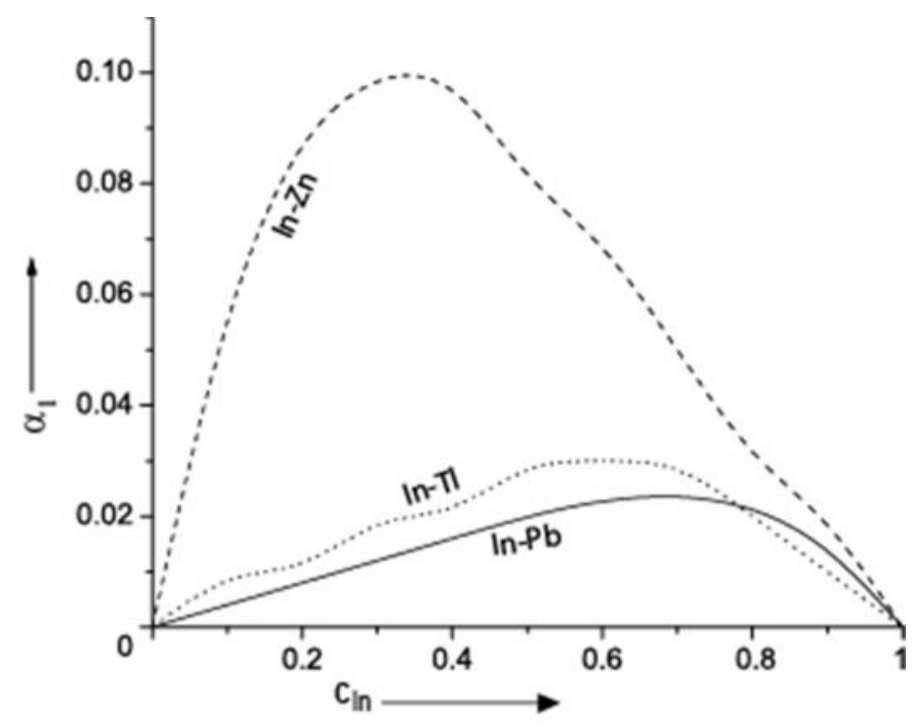

Fig. 6: Warren-Cowley short range order parameter, $\alpha_{1}$ of liquid In-Pb (673 K), In-Tl (723 K) and In$\mathrm{Zn}(700 \mathrm{~K})$ alloys versus concentration, $\mathrm{c}_{\mathrm{In}}$ of In-component: Solid curve [In-Pb]; Thin dotted curve [In-Tl]; Dashed curve [In-Zn]

It is interesting to note that both sign and the order of magnitude of $\alpha_{1}$ in all the three alloys are in conformity with the same in the order energy parameter, $\mathrm{W}$, indicating the segregating nature of the alloys. It is clear from small positive values of $\alpha_{1}$ that the In- $\mathrm{Pb}, \mathrm{In}-\mathrm{Tl}$ and $\mathrm{In}-\mathrm{Zn}$ liquid alloys have weak tendency of segregation, the degree of segregation being comparable in In-Pb and In- $\mathrm{Tl}$ alloys and relatively much larger in the In-Zn alloy.

\section{Conclusion}

The theoretical analysis reveals that quasi-chemical analysis successfully explains the observed properties of the In- $\mathrm{Pb}, \mathrm{In}-\mathrm{Tl}$ and In-Zn liquid alloys. Positive deviation of the thermodynamic properties of the alloys from the Raoultian solution behaviour indicates that the alloys are weakly segregating in nature. The comparative assessment of the interaction energy and the microscopic properties suggests that the degree of segregation is greatest in $\mathrm{In}-\mathrm{Zn}$ alloy and comparable in $\mathrm{In}-\mathrm{Pb}$ and $\mathrm{In}-\mathrm{Tl}$ alloys.

\section{Acknowledgements}

One of the authors, R.P. Koirala, is grateful to retired Prof. Dr. L.N. Jha and Prof. Dr. Pradeep Raj Pradhan (Post-Graduate Department of Physics, M.M.A.M. Campus, T.U., Biratnagar, Nepal) and Prof. Dr. Ashok Kumar (Post-Graduate Department of Physics, M.M.A.M. Campus, T.U., Biratnagar, Nepal) for their fruitful suggestions and inspiring discussions. 


\section{References}

[1] R. Hultgren, P.D. Desai, D.T. Hawkins, M. Gleiser, K.K. Kelly, Selected values of the thermodynamic properties of binary alloys (ASM, Metal Park, OH), 1973.

[2] A. B. Bhatia and R. N. Singh, Phys. and Chem. Liq., 11(1982) 285.

http://dx.doi.org/10.1080/00319108208080752

[3] J. A. Alonso and N. H. March, Physica B+C, 114 (1982) 67. http://dx.doi.org/10.1016/0378-4363(82)90008-0

[4] R.N. Singh, Can. J. Phys., 65 (1987) 309. http://dx.doi.org/10.1139/p87-038

[5] I. S. Jha, R. N. Singh, P. L. Srivastava and N. R. Mitra, Philos. Mag. B, 61 (1990) 15. http://dx.doi.org/10.1080/13642819008208649

[6] R. N. Singh, I. K. Mishra and V. N. Singh, J. Phys.: Condens. Matter, 2 (1990) 8457. http://dx.doi.org/10.1088/0953-8984/2/42/022

[7] L. C. Prasad, R. N. Singh, V. N. Singh, S. K. Chatterjee, Physica B: Condens. Matter, 215 (1995) 225. http://dx.doi.org/10.1016/0921-4526(95)00393-N

[8] R. N Singh and F. Sommer, Rep. Prog. Phys., 60 (1997) 57. http://dx.doi.org/10.1088/0034-4885/60/1/003

[9] R. N. Singh, F. Sommer, Phys. Chem. Liq., 36 (1998) 17. http://dx.doi.org/10.1080/00319109808035917

[10] R. Novakovic, M.L. Muolo and A. Passerone, Surf. Sci., 549 (2004) 281. http://dx.doi.org/10.1016/j.susc.2003.12.006

[11] L. C. Prasad and R. K. Jha, Phys. Status Solidi A, 202 (2005) 2709. http://dx.doi.org/10.1002/pssa.200520080

[12] B. C. Anusionwu, C. A. Madu and C. E. Orji, PRAMANA, 72 (2009) 951. http://dx.doi.org/10.1007/s12043-009-0088-6

[13] D. Adhikari, I. S. Jha and B. P. Singh, Philos. Mag., 90 (2010) 2687. http://dx.doi.org/10.1080/14786431003745302

[14] R. Novakovic, J. Non-Cryst. Solids, 356 (2010) 1593. http://dx.doi.org/10.1016/j.jnoncrysol2010.05.055

[15] A Kumar, I. S. Jha and B. P. Singh, Physica B: Condens. Matter, 406 (2011) 4338. http://dx.doi.org/10.1016/j.physb.2011.08.060

[16] I.S. Jha, D. Adhikari and B.P. Singh, Phys. Chem. Liq., 50 (2012) 199. http://dx.doi.org/10.1080/00319104.2011.569887

[17] D. Adhikari, B.P. Singh and I.S. Jha, Phase Transitions, 85 (2012) 675. http://dx.doi.org/10.1080/01411594.2011.635903

[18] R. P. Koirala, J. Kumar, B. P. Singh and D. Adhikari, J. Non-Cryst. Solids, 394 (2014) 9. http://dx.doi.org/10.1016/j.molliq.2012.12.008

[19] E. Ricci, S. Amore, D. Giuranno, R. Novakovic, A. Tuissi, N. Sobczak, R. Nowak, B. Korpala and G. Bruzda, J. Chem. Phys., 140 (2014) 214704-1. http://dx.doi.org/10.1063/1.4879775

[20] R.P. Koirala, I.S. Jha, B.P. Singh and D. Adhikari, BIBECHANA, 11 (2014) 46. http://dx.doi.org/10.3126/bibechana.v11i0.10379

[21] B. P. Singh, R. P. Koirala, I. S. Jha and D. Adhikari, Appl. Phys. A , 120 (2015) 1347. http://dx.doi.org/10.1007/s00339-015-9316-8 
[22] C. L. Wilson, E. A. Peretti, Ind. Eng. Chem., 28 (1936) 204.

http://dx.doi.org/10.1021/ie50314a013

[23] O.J. Kleppa, Acta Metall., 6 (1958) 225.

http://dx.doi.org/10.1016/0001-6160(58)90141-X

[24] J. Patel and S. Ahmed, Mater. Sci. Technol., 12 (1978) 147. http://dx.doi.org/10.1179/msc.1978.12.3.147

[25] J. Dutkiewicz and W. Zakulski, Bull. Alloy Phase Diagrams, 5 (1984) 284.

[26] O. E. Awe, O. Akinlade, and L. A. Hussain, Z. Metallkd., 96 (2005) 89. http://dx.doi.org/10.3139/146.018076

[27] E. O. Ilo-Okekea, B. C. Anusionwua and O. Popoola, Phys. Chem. Liq., 43( 2005) 333. http://dx.doi.org/10.1080/00319100500087964

[28] J.-E. Lee, K.-S. Kim, K. Suganuma, M. Inoue and G. Izuta, Mater. Trans. JIM， 48 (2007) 584. http://dx.doi.org/10.2320/matertrans.48.584

[29] I. Koirala, I. S. Jha, B. P. Singh and D. Adhikari, Physica B: Condens. Matter, 423 (2013) 49. http://dx.doi.org/10.1016/j.physb.2013.04.051

[30] J. Pstrus, Z. Moser, W. Gasior, Appl. Surf. Sci., 257 (2011) 3867. http://dx.doi.org/10.1016/j.apsusc.2010.11.076

[31] I. Koirala · B.P. Singh · I.S. Jha, J. Non-Cryst. Solids, 398-399 (2014) 26. http://dx.doi.org/10.1016/j.jnoncrysol.2014.04.018 